\title{
O Ronco do V8 Objeto de Desejo: Estudo de Caso do Automóvel Ford Maverick em Diferentes Gerações sob a Ótica das Cadeias Meio Fim
}

The roar of the $\mathrm{V} 8$ object of desire: study of case from the Ford Maverick Automobile in different generations under the Mean-EndChains view.

Alexandre Borba da Silveira, Unisinos Business School, Porto Alegre-RS, Brasil (alexandre.silveirars@gmail.com) Gabriel Roberto Dellacasa Levrini, Escola Superior de Propaganda eMarketing Sul, Porto Alegre-RS, Brasil (levrini@terra.com.br)

\section{RESUMO}

No início do ano de 1970, a Ford do Brasil S.A., trouxe um campeão de vendas dos USA, o Ford Maverick. O automovel caiu rapidamente no gosto popular, neste novo segmento de carros médios, passando a ter uma legião de admiradores. Esta pesquisa objetiva, a luz da teoria das cadeias meio-fim, comparar o comportamento e valores de usuários do Maverick de duas diferentes gerações em épocas diferentes: nos anos 1970 quando o automóvel foi lançado, cujos principais consumidores eram da geração Baby Boomers e dos filhos desta geração, a geração X. Para este estudo foi utilizado a técnica de laddering, com entrevistas em profundidade com 47 entrevistados, sendo 20 pertencentes a geração Baby Boomers (indivíduos nascidos entre 1940 e 1960) e os outros 27 entrevistados, nascidos entre 1970 e 1990 que fazem parte da geração X, em que seus depoimentos permitiram acomparação das gerações. Os resultados da análise de conteúdo e da análise utilizando o laddering permitiu o desenvolvimento de mapas hierárquicos dos valores respectivos de cada geração. Estes mapas deram como resultado: a geração Baby Boomers demostrou como valor fundamental para a aquisição do Maverick na época a questão da segurança financeira e motor potente $V 8$ como maior fator motivacional para aquisição deste automóvel. No caso da geração $X$ 
estudo indicou como esperado, o valor nostalgia e saudosismo como maior impulsionador para ainda ter este automóvel, seja como colecionador ou hobby. As gerações apresentam como em comum, o valor de nostalgia e saudosismo. Os resultados sugerem novas abordagens para os estudos do comportamentode consumo e marketing geracional.

Palavras-chave: Nostalgia; Gerações; Laddering; Saudosismo; Maverick.

\begin{abstract}
At the beginning of 1970, Ford do Brasil S.A. brought to Brazil theUSA sales' champion, the Ford Maverick. The car quickly fell intopopular taste, in this new segment of medium cars, having a legion of admirers still to actual days. The objective of our research, at the light of Means-End Chain Theory, is to compare Maverick users' behaviors and values, from two different generations at different times: in the 1970s when the car was launched, whose main consumers were the Baby Boomers generation and the sons of this generation, generation $X$. For thisstudy, using laddering technique, 47 in-depth interviews, with, 20 belonging to the Baby Boomers Generation (individuals born between 1940 and 1960) and the other 27 individuals, born between 1970 and 1990 that belong to $X$ Generation, in which their testimonies allowed the comparison between generations. The content analysis results and the laddering analysis, allowed the development of hierarchical maps for each generation values. These maps showed the following results: Baby Boomers Generation demonstrated as a fundamental value for the acquisition of Maverick in the 70s financial security importance and a powerful V8 engine that was the biggest motivational factor for the acquisition of this car. In the case of Generation X, the study indicated, as expected, the value of nostalgia and love forthe oldies, as the biggest driver for more than 40 years later, stillhaving this car, whether as a collector or hobby. The generationsstudy presented, as in common, the nostalgia value. The study results indicated, as expected, the nostalgia and oldies love's values as the biggest driver to still have this car, whether as a collector or hobby. The generations present, as in common, thesevalues. The results suggest new research line and approaches forthe studies of consumer behavior and generational marketing.
\end{abstract}

Keywords: Nostalgia; Memories; Generations; Laddering; Maverick. 


\section{INTRODUÇÃO}

Os produtos e os automóveis em geral têm seu ciclo de vida que na literatura é dividido em quatro estágios: introdução, crescimento, maturidade e declínio (Wasson, 1978). No entanto, o consumo ocorre a partir de uma experiência complexa rodeada de aspectos racionais e emocionais (Carvalho e dos Santos, 2019). Neste sentido, os produtos e serviços possuem em seu ciclo de vida o poder de carregar e comunicar significados além de sua característica utilitária (Carvalho e dos Santos, 2019). Portanto, dado o ciclo de vida cada vez menor dos produtos e serviço devido a velocidade da introdução de novas tecnologias verifica-se uma certa instabilidade de escolha, que leva a uma tendência de sentimento de nostalgia (Silva et al., 2020).

Diante desta perspectiva, este estudo analisou o ciclo de vida do automóvel Ford Maverick, que sobreviveu por mais de duas décadas ultrapassando gerações, sendo admirado até os dias de hoje pelos seus fãs e colecionadores. O Ford Maverick, foi oficialmente lançado nos EUA em 1969, a partir da invasão dos carros europeus e principalmente os carros médios japoneses no mercado americano. O Maverick era um carro com características e atributos simples: um automóvel médio, facil de dirigir, manutenção barata, mas com uma aparência inspirada no Mustang, o que por si só já foi uma inspirada inovação na época (Gregson, 2011).

Apesar de ter uma versão de carro familiar, prático, moderno e econômico, foi lançado com versão esportiva e um potente motor V8, que passou a ser objeto de desejo dos jovens americanos. Rapidamente, pelos seus atributos, preço e versatilidade em primeiro ano no mercado vendeu 
579.000 unidades nos EUA, um verdadeiro recorde para automóveis recém lançados foi aumentando a cada ano. Nesta época, a Ford no Brasil comercializava dois modelos com bastante sucesso: o Corcel e o Galaxie, o automóvel mais luxuoso no momento no mercado.

No entanto, o mercado estava aberto para carros médios, intermediários entre os populares e os de luxo, existia um espaço a ser preenchido no mercado rapidamente percebido pelas montadoras, onde apenas os modelos Aero-Willys e Itamaraty (versão luxuosa do Aero), que já estavam ficando ultrapassados com inúmeros problemas mecânicos. Assim, aproveitando a quase impossibilidade de importação as montadoras presentes no Brasil devido a crises do petróleo, econômicas e cambiais, lançaram vários modelos como o Opala da GM e o Passat da VW (Gregson, 2011).

Enquanto a Ford, trouxe para o Brasil seu campeão de vendas nos EUA, o Ford Maverick no ano de 1973. Um automóvel com um design arrojado, motor potente e que tinha uma dupla versão familiar, mas tinha uma vocação esportiva muito grande pela sua semelhança com o Mustang, objeto de desejo de quase todos os jovens da época (Gregson, 2011).

O Maverick GT e as outras versões atingiram vendas significativas, o esportivo chegou a 2.000 unidades 1973 e mais de 4.000 em 1974. Desta forma, uma profunda mudança de mercado a nível mundial surgiu a partir da crise do petróleo para um país importador e dependente do petróleo no final dos anos 70, e se tornou um problema pelo seu consumo ao bolso dos consumidores.

Como o Marverick pela sua potência não era econômico, ganhou fama de "Beberrão de gasolina", e foi caindo em desgraça com essa profunda mudança de mercado que passou a buscar automóveis mais econômicos. Depois de ter vendido mais de 100.000 unidades em 1979 o lendário Maverick saia de linha para dar lugar ao Corcel II, com características mais ajustadas as necessidades dos consumidores da época (Gregson, 2011). 
Viver experiências históricas e sociais, sejam individuais ou coletivas, podem fazer surgir uma identificação, como pertencer a um grupo: "wesense" (Corsten, 1999). Neste sentido, os consumidores de diferentes gerações interessam-se em participar de movimentos, grupos ou comunidades que compartilham interesses, atitudes e percepções semelhantes perante um produto ou marca (Lyu e Kim, 2020). Assim, o consumo desenvolve identidades quando escolhemos, experienciamos e compramos algo demonstrando a forma como visualizamos o mundo ao nosso redor (Carvalho e dos Santos, 2019; Silva et al., 2020).

A possibilidade de encontrar valores semelhantes nas diferentes gerações relativas a um mesmo produto em épocas diversas abre novos rumos no marketing de gerações podendo ser utilizado em campanhas publicitárias nos dias atuais. Pais, filhos e netos operam em mundos simbolicamente distintos, em constante transformação, de acordo com ocorrências históricas e dos relativos grupos sociais em que está inserido, sempre em construção e com fronteiras flexíveis (Barth, 1996).

O objetivo de pesquisa foi de comparar o comportamento e motivações dos consumidores do automóvel Maverick de duas diferentes gerações (Baby Boomers e Geração X). Os indivíduos da geração baby boomers eram os compradores do Maverick da época, ou seja, do ciclo de vida do Maverick nos anos 70. A Geração X nesta época eram adolescentes, jovens que já admiravam estes automóveis e muitos hoje são colecionadores, ou tem um profundo sentimento de nostalgia pelo automóvel Maverick. Em censo realizado pela Datafolha (2008) entre jovens de 15 a 25 o maior objeto de desejo ou sonho de consumos eram carros e motos chegando a $40 \%$, enquanto moradia e artigos de informatica respondiam $15 \%$ e $20 \%$.

Neste estudo é proposto um processo comparativo de duas gerações sobre como os valores dos consumidores influenciam a escolha por determinado produto. Inicialmente ocorre com uma avaliação do significado utilitário do produto. Segundo os autores Vinson, Scott e Lamont, 
(1977), os consumidores utilizam um julgamento passo-a-passo em detalhes, avaliando os benefícios ou contras do produto, desta forma promovendo uma Motivação Instrumental. Posteriormente, os valores humanos destes individuos são contemplados por esses consumidores determinando quais atributos tangíveis são importantes para eles; na prática, segundo os autores, os consumidores comparam os atributos tangíveis do produto com aqueles atributos tangíveis preferidos por eles e escolhem o produto que mais se aproxima.

No entanto, quando os consumidores avaliam o significado simbólico do produto, usam um julgamento afetivo, atribuindo um significado emocional para o produto, valores que diretamente influenciam a escolha do produto diretamente. Em particular, os indivíduos comparam os valores culturais simbolizados pelo produto aos seus valores, escolhendo o produto que tem maior congruência (Vinson, Scott e Lamont, 1977). Neste sentido a principal contribuição do estudo está em traduzir as experiências dos consumidores por meio de suas memórias e lembranças passados com os produtos e ou serviços (|zquierdo, 2018; Lyu e Kim, 2020).

\section{REFERENCIAL TEÓRICO}

\section{Comportamento do consumidor}

O valor hedônico dos produtos, tem importãncia direta para os domínios emocionais, experimentais e simbólicos do consumo porque suscita o surgimento das emoções de prazer e excitação. O valor utilitário dos produtos está primeiramente direcionado às metas e objetivos (Hirschman e Holbrook, 1982). As tarefas cotidianas, como trabalho, comportamento, alguns hábitos de consumo e a utilização do tempo para realizar seus desejos, como os hobbies, eventos sociais, diversão tende a seguir um padrão de valores dos indivíduos (Solomon, 2016).

Valores de acordo com Blackwell, Miniard e Engel (2000) são crenças compartilhadas ou a adoção de normas grupais internalizadas pelos indivíduos em relação a sua vida e os comportamentos sociais. O conjunto 
de valores de um indivíduo prova forte influência no seu processo de decisão de compra e consumo, indicando as metas, as motivações e os meios pelos quais os individuos atingem estas metas (Rokeach, 1972; Solomon, 2016). Assim, aquilo que um indivíduo entende como correto e recomendável podeser considerado um valor (Rezsohazy, 2001).

O comportamento padrão de um indivíduo, motivado pelos seus valores pessoais, influencia as preferências e escolhas que este faz, geralmente de acordo aos valores sociais da sociedade em que está inserido e em relação ao sistema de valores aos quais está exposto. Assim, o comportamento é influenciado pelos valores ajudando a moldar preferências, desejos e escolhas, operacionalização e usos (Blackwell, Miniard e Engel, 2000). Para Silva et al. (2020) existem modelos e motivações de consumo que identificam ações relevantes gerados por fatores internos (hedonismo, perfeccionismo e a nostalgia) e fatores externos (esnobismo e de adesão) a produtos e a serviços.

Diante desta perspectiva, O consumo ocorre devido a uma forma não verbal de apresentação da personalidade do consumidor perante um produto e serviço (Carvalho e dos Santos, 2019). Neste sentido o comportamento do consumidor busca analisar os fenômenos sociais capaz de verificar como ocorrem as experiências com um produto ou serviço além de demonstrar como as crenças, atitudes, valores e consequências influenciam nossas escolhas presentes, passadas e futuras (Silva et al., 2020). Para Zeithaml et al. (1990) estes elementos vinculam a compra ou o consumo aos valores pessoais dos consumidores. Desta forma as inter-relações atributosconsequências-valor constituem o centro desta teoria. Os valores são identificados através da representação da cadeia meios-fim que buscam explicar a procura nostálgica a aquisição de um automóvel Ford Maverick atualmente. 


\section{Teoria das Cadeias Meios-Fim}

Gutman (1981) conceitua o modelo cadeia meios-fim, de forma que os "meios" significam os produtos ou serviços nos quais a pessoas se engajam. A situação de experiência valorada seria o "fim", por exemplo, felicidade, segurança e realização.

O conceito de valor do cliente é fundamentado como uma percepção com estruturas hierárquicas e que os valores pessoais são uma condição abstrata na situação de consumo (Rokeach,1972). Os autores Woodruff e Gardial (1996) definem valor do cliente como sendo a percepção do consumidor em relação ao seu desejo. Os mesmos autores explicam que a teoria de cadeias de meios-fim é uma forma de ponderar sistematicamente a representação hierárquica, entre produtos e consumidores que se relacionam em três níveis:

a) Atributo (A) - no nível mais sólido e mais próximo ao bem ou serviço em si. Os consumidores geralmente mencionam estes atributos quando perguntados sobre um produto. Os atributos sólidos são compreendidos e identificados nos bens e/ou serviços; por outro lado, os atributos abstratos são particularidades de bens e/ou serviços. Estes atributos não são inteiramente identificados ou percebidos através dos sentidos (Gutman, 1981).

b) Consequência (C) - são dados intermediários da cadeia. Podem ser identificados como positivos ou negativos, a partir da experiência e utilização de um bem ou serviço (Peter e Olson, 2010).

c) Valor (V) - é o nível mais elevado da hierarquia, onde intençõesou condições desejadas alcançam o processo de tomada de decisão, seja na utilização de um serviço ou na compra de um bem. Os valores terminais traduzem as circunstâncias resultantes da experiência, guiando o comportamento dos indivíduos. Os valores instrumentais, por sua vez, são ações comportamentais preferenciais que os indivíduos utilizam para alcançar os valores terminais (Allen, 2001; Solomon, 2016). 
Reynolds e Gutman (1988) explicam que cada consumidor tem uma percepção, em que a consequência decorre da utilização do produto. Desta forma, entende-se que o encadeamento atributo-consequência-valor (A-C-V) o e o pivô do modelo, onde uma composição faz uma conexão dos atributos de produtos, suas consequências geradas e a razão para atribuir valor, porque elas são importantes. Walker e Olson (1991) sugerem que a teoria da cadeia meios-fim fornece um molde que permite a observação e a interpretação de como é percebido pelos consumidores os produtos com relação a si próprios, porque descreve a relação entre os atributos e valores (benefícios) que podem gerar satisfação.

O conjunto da hierarquia de valores é graficamente simbolizado por um Mapa Hierárquico de Valor (MHV) que realiza a conexão entre os atributos, consequências e valores pessoais ligados a um produto ou serviço. As diversas cadeias meios-fim estruturadas em um MHV apontam a conexão entre todos os atributos, benefícios e valores pessoais relativos aos bens e serviços ponderados (Reynolds e Gutman, 1988; Santos e Johnston, 2018).

\section{As Gerações}

Gerações são agrupamentos de pessoas que compartilham experiências e são influenciados pela época em que vivem (Kotler e Keller, 2006). Além disso, podem também influenciar as gerações seguintes. Adicionalmente, cada geração é fortemente influenciada pelo meio ao qual é desenvolvida pois existem diferenças de valores e atitudes entre os grupos de idade (Kotler e Keller, 2006; Solomon, 2016). Desta forma, a idade é uma variante que convém para identificar as contestações de valores sobre produtos (Silva et al., 2020). O consumo torna-se o desenvolvedor da identidade do consumidor moldando a forma de ver o mundo e proporcionando um sentimento de pertencimento a um grupo ou geração (Silva et al., 2020).

Neste sentido, existe uma necessidade de entender mercadologicamente as diferentes percepções das gerações por meio dos 
O Ronco do V8 Objeto de Desejo: Estudo de Caso do Automóvel Ford MaverickemDiferentes Gerações sob a Ótica da Cadeias Meio Fim 10

eventos históricos e acontecimentos que têm influências significativas nos valores de cada indivíduo (Erickson, 2011; Silva et al., 2020). Para Oliveira (2010) ao refletir sobre gerações, devemos considerar a antiga formação clássica de três gerações: como o avô, o pai e o filho foram influenciados cada um pelos eventos do seu tempo e pelos valores familiares incorporados. Para efeito desta pesquisa, comparamos as características conhecidas de duas gerações que conviveram com o ciclo de vida do automovel Maverick. São elas: Geração Baby Boomers e X.

\section{Geração Baby Boomers}

De acordo Erickson (2011) a geração Baby Boomers é composta de pessoas que nasceram entre 1940 e 1960. A formação de valores de cada geração, geralmente acontece na adolescência, em que ocorreu nesta entre os anos 1960 e 1970. Nesta época ainda surgiu o movimento hippie propagando a ideia de "paz e amor", com uma juventude a fim de externar suas opiniões opostas a sociedade moralista, racista, consumista e tecnocrata (Brandão e Duarte, 2004).

No Brasil da época, havia uma grande descrença política, os estudantes tornaram-se militantes políticos e a música foi utilizada para conscientizar as classes mais populares. Durante os anos 1970 houve crise política, crise econômica, aumento do petróleo, inflação exorbitante, políticos mentirosos, desvalorização da moeda brasileira, endividamento externo e os movimentos populares se reorganizando, manifestações estudantis voltaram e greves começaram a acontecer.

Estes eventos vivenciados pela Geração Baby Boomers os fizeram tornarem céticos em relação as autoridades, a não acreditarem mais nos governantes (Erickson, 2011).

\section{Geração X}

A Geração X são pessoas nascidas entre 1960 e 1979, com sua adolescência entre os anos 1980 e 1990. A Geração X teve na sua 
adolescência, um período de incertezas e mudanças sociais (Erickson, 2011). Os anos 1980 confirmaram o conservadorismo e o consumismo gerados pela da indústria cultural concebida na década de 1970. Os jovens dos anos 80 continuaram a levantar bandeiras e defender ideais importantes como a preservação do meio ambiente e protestaram contra o progresso industrial descabido. Nesta mesma época, o Brasil se deparava em uma imensa crise econômica, decorrente do período da ditadura (Brandão e Duarte, 2004). Erickson (2011) destaca como características da Geração X diante de suas vivências, a capacidade de lidar com qualquer situação, bons pais, bons amigos, escolhem como querem passar o tempo contrabalanceando suas atividades. Os Baby Boomers esperavam que seus filhos fossem bemsucedidos, já a Geração X esperam ser bons pais. Outras características da Geração X, são o cumprimento de suas obrigações, seriedade e comprometimento com seus empregos, a busca pela auto independência, realizações empresariais, usuários da tecnologia e com tendência a inovação.

\section{Colecionismo e Nostalgia}

Com base na perspectiva experimental dos consumidores 0 colecionismo é um tipo comportamento que Slater (2001) define como um processo de obter e possuir objetos de maneira ativa e apaixonada. Já Murphy (2000) destaca que para a maioria dos colecionadores, seu hobby representa contentamento, um instinto em busca do belo ou o anseio de preservar a história. Existem diferentes motivações para se colecionar, o que se torna difícil de formar uma teoria sobre o colecionismo (Belk,1995). O sentimento de nostalgia surge como um grande impulsionador para que o colecionador obtenha e detenha elementos do passado, e dessa forma recordar dos bons momentos que experimentou.

\section{METODOLOGIA}


O Ronco do V8 Objeto de Desejo: Estudo de Caso do Automóvel Ford MaverickemDiferentes Gerações sob a Ótica da Cadeias Meio Fim 12

Esta pesquisa tem caráter exploratório, uma vez que o tema proposto tem um caráter de explorar um fenômeno. Conforme proposto por Gil (2014), a exploração proporciona uma visão geral acerca de um tema pouco explorado, no qual se torna difícil a formulação de hipóteses. A abordagem do estudo e qualitativa, dado que não se busca uma generalização dos dados coletados, mas sim uma investigação dos comportamentos e motivações dos compradores do automóvel Maverick de duas diferentes gerações (Baby Boomers e Geração X).

A estratégia utilizada nesta pesquisa exploratória envolveu a aplicação de entrevistas em profundidade, sendo que 27 indivíduos da Geração Baby-Boomers, que possuem ou possuíram automóveis Maverick, e 20 indivíduos da Geração X que igualmente possuíram ou possuem este automóvel nos dias de hoje, como reliquia ou coleção. Todas as entrevistas foram realizadas presencialmente sendo os locais das entrevistas escolhidos pelos entrevistados, buscando formas de os entrevistados sentirem-se confortáveis para contar suas histórias de vida e suas experiências com o Maverick, ou também na preservação desta paixão, através de feiras e encontros de colecionadores. Todos os participantes da pesquisa aceitaram os termos da pesquisa e deram consentimento para que suas respostas fossem analisadas e publicadas de acordo com o termo de consentimento de livre esclarecimento da pesquisa.

Foram selecionados participantes utilizando a técnica coleta snow ball, principalmente nestes encontros de colecionadores e feiras de carros antigos nos meses de agosto a setembro de 2019. A amostra foi um grupo de pessoas com idade igual ou superior a 65 anos (Baby Boomers) e outro grupo com pessoas entre 25 e 45 anos (Geração X), que possuem ou possuíram um automóvel Maverick. Todas as entrevistas foram gravadas e transcritas pelo pesquisador 1 na sua totalidade com a permissão dos entrevistados que foram orientados através da leitura e assinatura do termo de consentimentoe livre esclarecimento. Para a caracterização dos sujeitos da pesquisa, os nomes reais foram modificados para nomes fictícios. As quarenta e sete 
entrevistas foram todas transcritas e totalizaram mais de vinte horas e trinta minutos de gravações das seis questões abertas apresentadas para os entrevistados. Cada questão respondida levava para novos questionamentos em busca de uma maior profundidade das entrevistas encerrando em média com oito perguntas realizadas aos entrevistados.

Para análise dos dados utilizou-se a técnica do laddering com posterior análise de conteúdo. Laddering se refere a uma técnica de entrevista individual em profundidade, usada para desenvolver uma compreensão de como os consumidores traduzem os atributos dos produtos em associações significativas com respeito a si mesmo, seguindo a Teoria Means-End (Gutman, 1981; Reynolds e Gutman, 1988). Esta técnica envolve uma adaptação do formato de entrevista usando principalmente uma série de questões direcionadas e tipificadas pelo "por que isso é importante para você? "com o objetivo expresso de determinar conjuntos de ligações entreos elementos-chave de percepção em toda a gama de atributos (A), consequências (C) e valores (V). Essas redes de associação, ou escadas, conhecidas como orientações perceptivas, representam combinações de elementos que servem de base para distinguir entre produtos em uma determinada classe de produto (Gutman; 1981; Reynolds e Gutman, 1988).

Para complementar o estudo foi realizada análise de conteúdo das informações coletadas nas entrevistas para entender o comportamento dos consumidores analisados. Em estudos do comportamento do consumidor torna-se necessário analisar as falas que geram conteúdos que trazem significados relacionados ao consumo (Allen, 2001). A análise de conteúdo neste estudo teve como objetivo organizar e sintetizar os dados, com intuito de obter as respostas do tema pesquisado (Gil, 2014). Após transcrição das entrevistas, foram realizadas as três etapas principais na análise de conteúdo, conforme Bardin (2011, p. 148): pre-análise, exploração do material e, por fim, interpretação. Na pre-análise foi realizada a leitura detalhada e o preparo do material para que fosse explorado, por meio da categorização, definida pelos autores como um processo estruturalista que 
O Ronco do V8 Objeto de Desejo: Estudo de Caso do Automóvel Ford MaverickemDiferentes Gerações sob a Ótica da Cadeias Meio Fim 14

consiste na etapa de inventário, com o isolamento dos elementos e a classificação, que consiste em "procurar ou impor certa organização às informações coletadas nas entrevistas".

A importância da categorização nesta pesquisa se deu pelo fato de que o processo viabilizou o encontro de pontos comuns entre as experiênciase ideias informadas por todos os participantes, fazendo com que o fenômeno pudesse ser analisado e compreendido de maneira mais completa e ampla. A amostragem foi por conveniência, recomendada por Gil (2014) como o menos rigoroso tipo de amostragem, sem rigor estatístico. De acordo com o autor, essa amostragem e adequada para pesquisas exploratórias qualitativas, caso do presente estudo. Uma vez realizadas pesquisas em profundidade, não se faz necessária validação estatística.

\section{ANÁLISE DOS RESULTADOS}

Os dados obtidos foram transcritos e processados isolando-se os atributos, consequências e valores, com uma elaboração da uma tabela de ladders e criação do mapa hierárquico de valores (MHV). O uso desta técnica no desenvolvimento de informações úteis para a tomada de decisão de marketing foi aplicado em termos de segmentação perceptual, determinando os pesos de importância dos vários componentes dos ladderse desenvolvendo e avaliando a publicidade a partir desta perspectiva (Reynolds e Gutman, 2001).

Os resultados levaram em consideração a capacidade do Laddering de extrair do respondente a verdadeira base para qualquer conexão significativa que eles tenham com o produto ou neste caso com o automóvel Ford Maverick. Neste sentido, o mapa de hierarquia foi realizado a partir da identificação e análise conteúdos que resultaram em atributos, consequências e valores dos consumidores. Assim, o método laddering foi aliado ao mapa hierárquico (Hierarchical Valve Map - HVM) para revelar e apresentar as hierarquias da cadeia de meios e fim (Reynolds e Gutman 1988; dos Santos e Johnston, 2018). Assim, a análise ocorreu em quatro fases: 
Análise de conteúdo, Matriz de Implicação, Construção do mapa hierárquico de valor (HVM) e Determinação e identificação das percepções dominantes. Neste sentido, as entrevistas foram transcritas e os conteúdos analisados através da técnica de análise de conteúdo buscando identificar as variáveis relacionadas ao ciclo de vida do produto - automóvel Mavericke os sentimentos dos consumidores perante esse produto. Foram levantadas variáveis a partir da análise das respostas que geraram um conjunto de dados analisados para desenvolvimento da matriz, mapa e determinação dos atributos, consequências e valores. A matriz de implicação e mapa hierárquico foram desenvolvidos para representar as interações entre os conteúdos, informações e falas dos entrevistados. Segundo dos Santos e Johnston (2018) estes elementos são colocados nas linhas e colunas sendo o interior da matriz numerado que demonstra quantas vezes um elemento pode levar ao outro identificando assim as interações existentes no mapa.

O mapa hierárquico de valor (HVM) é uma representação gráfica no desenho que se assemelha a uma árvore que apresenta as respostas dos entrevistados que representa a linha de raciocínio do consumidor quando consome um determinado produto ou serviço (Reynolds e Gutman 1988; dos Santos e Johnston, 2018). O estudo utilizou como guia as sequências que surgiram a partir das respostas dos entrevistados analisadas nas interações visualizadas pela matriz de implicação que determinaram as percepções sobre o automóvel Maverick. Na última etapa foram analisadas as relações de forma direta $e$ indireta que formaram a sequência AtributosConsequências-Valores para considerar as cadeias em destaque nestas interações. Seguindo as recomendações de dos Santos e Johnston (2018) não priorizamos o lado quantitativo nesta pesquisa, pois a importância da apresentação da cadeia de meios e fim deve ser levada com cautela analisando o contexto ao qual a pesquisa foi realizada e analisada. Portanto a próxima fase é identificar os atributos, consequências e valores da geração $x$ perante o produto automóvel Ford Maverick. 
O Ronco do V8 Objeto de Desejo: Estudo de Caso do Automóvel Ford MaverickemDiferentes Gerações sob a Ótica da Cadeias Meio Fim 16

\section{Identificações de Atributos, Consequências e Valores da Geração X}

A seguir na tabela 1 e Figura 1 são listados os Códigos e o Mapa de Valores encontrados nas entrevistas com a Geração X:

Tabela 1 - Lista de códigos-resumo Geração X

\begin{tabular}{|c|c|c|}
\hline \multicolumn{3}{|c|}{ Listagem dos códigos dos conteúdos analisados: Geração X } \\
\hline Afributos & Consequências & Valores \\
\hline 1 - Estilo do automóvel & 16 - Marca chama a atençāo & 23 - Nostalgia/Saudosismo da marca \\
\hline 2 - Design do automóvel & 17 -Preço & 24 - Marca remete a status \\
\hline 3 - Potência do motor & 18 - Colecionismo & 25 - Auto-estima \\
\hline 4-Manutençāo & 19 - Qualidade & 26 - Qualidade de vida \\
\hline 5 - Durabilidade do automóvel & 20 - Nostalgia/Infância & 27 - Sentimento de realizaçāo \\
\hline 6- Dirigibilidade do automóvel & 21 - Confiança na marca & 28 - Segurança financeira \\
\hline 7 - Ronco do motor & 22 - Velocidade/Potência & 29 - Amor/Familia \\
\hline 8 - Robustez do automóvel & & 30 - Estou colaborando com o pais \\
\hline 9- Conforto do automóvel & & \\
\hline $10-$ Marca & & \\
\hline 11 - Oportunidade de negócio & & \\
\hline 12 - Marketing realizado & & \\
\hline 13 - Custo $x$ beneficios & & \\
\hline 14 - História/fama do automóvel & & \\
\hline 15 - Reputaçāo familiar da marca Ford & & \\
\hline
\end{tabular}

Fonte: Os autores (2019)

Figura 1: Mapa de Hierarquia de Valores da Geração X 


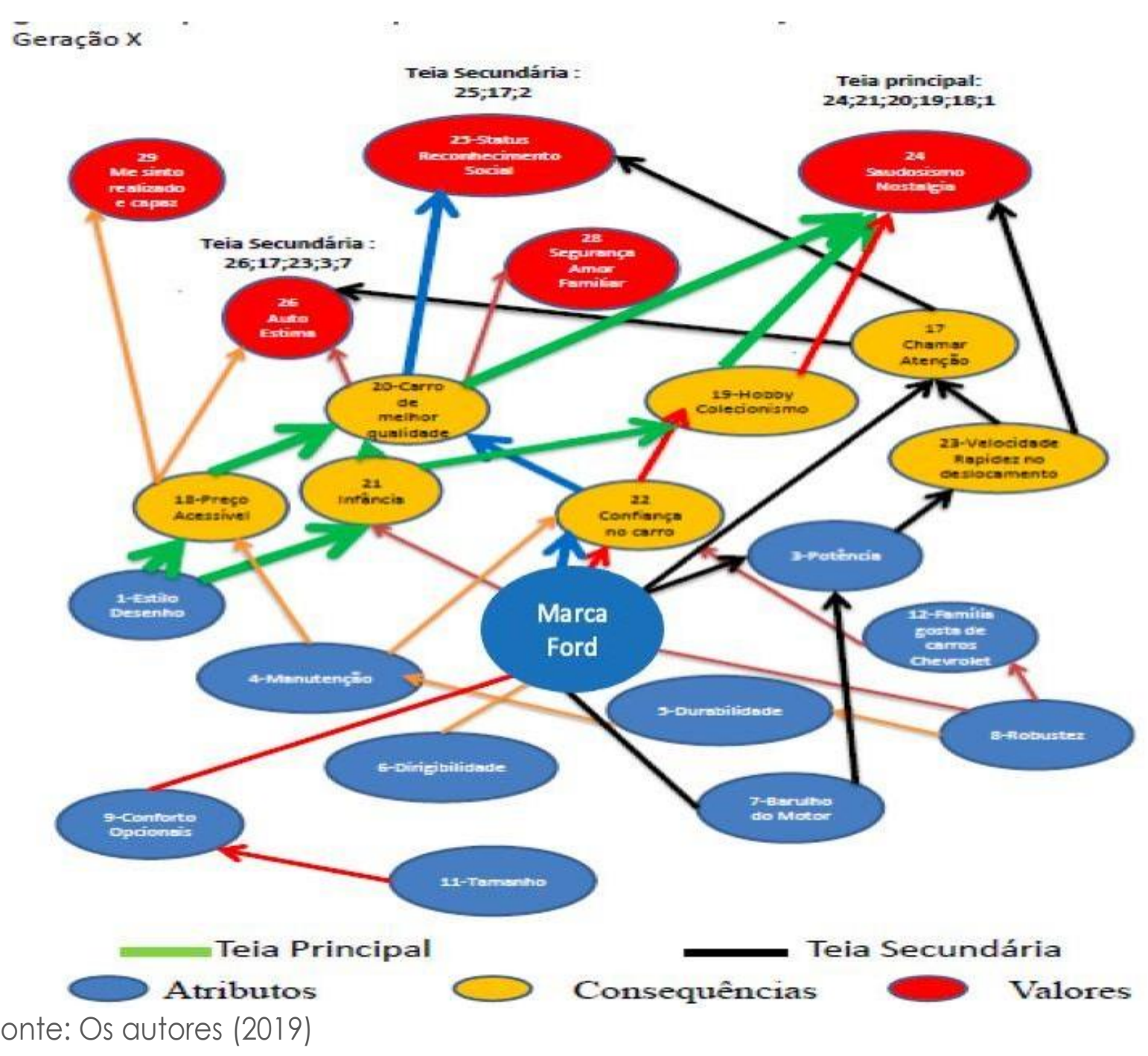

A pesquisa aponta como principal valor a Nostalgia e o Saudosismo, e ainda quatro teias de valores secundários, a Autoestima, Status, Segurança ea Realização. Isto vai de acordo com as características da Geração X como compromisso, respeito e família.

\section{Status, Segurança e Realização}

Em relação ao status, o entrevistado 7, ilustra esta percepção ao afirmar que:

[...] e essa questão de gostar da marca Ford isso faz parte da família [...] meu avô só gostava de carros desta marca, não gostava de outras, eu também [...] minha mãe, minha irmã [...] todo mundo isso nos dá poder. (Entrevistado 7, 41 anos). 
Ah, é uma máquina de quebrar pescoço [...] onde tu passar o pessoal olha, é um orgulho. (Entrevistado 6, 68 anos).

E um carro diferenciado, que é destaque por ter motor diferente. Você passa na rua o pessoal que conhece já vê que é algo diferente, você se sente muito bem. (Entrevistado 5, 71 anos).

[...] eu acho que o Maverick de 2 portas marcou uma época sim, era status, reconhecimento de alguém especial [...] lembra muito do "Muscle-Car" americano, embora o Maverick não fosse exatamente isso[...],mas lembra sim o desenho, aquela caída do teto, arrojado , esportivo. (Entrevistado 8, 74 anos).

Neste relato é possível reconhecer o citado nos trabalhos de Jones (2004) e Brown, Kozinets, e Sherry,(2003) ao revelar que as marcas famosas entusiasmam a recompra. Notou-se nos entrevistados uma sensação de confiança e orgulho por ter o bem que sempre esteve presente na família.

\section{Autoestima}

O Maverick inspirava modernidade, sua semelhança ao Mustang, um dos automóveis mais desejados no mundo, provocava uma relação intensa, seu roco do potente motor $\mathrm{V} 8$ era saudado por todos. Ainda o modelo apresentava uma qualidade superior e nos relatos sempre aparece como um elemento que elevava a autoestima dos usuários:

O Maverick chamava muito a atenção, fazia bem ver meu pai dirigindo um, meus amigos tinham o maior ciúme [...] (Entrevistado 3, 54 anos).

Os homens da minha família só falavam do Maverick, que era o melhor, o mais moderno e esportivo...eu ouvia tudo isso e tinha orgulho que meu pai tivesse um Maverick [...] (Entrevistado 2, 52 anos).

As pessoas bacanas famosas tinham Mavericks, quando meu pai comprou um foi algo incrível, maior orgulho, lembro disso e sinto isso até hoje com meu atual um Modelo super inteiro 1975 (Entrevistado 8, 48 anos). 
Nostalgia e Saudosismo

A questão da infância foi muito ressaltada, onde detalhes do carro que não é mais fabricado foram lembrados, levando a resgate de momentos passados, geralmente na infância e com o pai ou familiar como possuidor de um Maverick.

[...] quando meus pais se separaram eu era muito jovem, mas quando eles ainda eram casados ele tinha um Maverick e eu lembro até hoje que meu pai fala que era o melhor carro que ele já teve.(Entrevistado 10, 52 anos).

[...] teve uma vez que eu fui trocar a surdina do Maverick, que ronco espetacular e vi um rapaz de uns 35 anos com seu filho de 5 ou 6 anos de idade chegou perto do meu carro, apontou pro carro e falou pro filho dele: Tá vendo isso aqui meu filho [...] isso aqui é um carro de verdade [...] isso aqui não é essas porcarias que a gente tem hoje.(Entrevistado 9, 75 anos).

[...] era outra época, a gente ia à praia, parava no túnel verde, por exemplo, para fazer um lanche, seguia viagem, era bom e os vários Mavericks que o pai teve a gente sempre andava, era ótimo, que saudade! (Entrevistado 6, 71 anos).

Um dos pontos centrais nas entrevistas da Geração X, foi a questão da preservação do bem como forma de perpetuar a memória que ele representa. Esta cadeia de elementos nos leva ao principal valor encontrado, a nostalgia e saudosismo. A questão da infância onde a lembrança de pais, tios, avós com o Maverick é latente, nos sugere que a importância que a Geração X dá para o carro, na realidade é um resgate de uma época que passou e deixou marcas. No Quadro 2 a seguir lista dos códigos e o mapa de valores encontrados nas entrevistas com os Baby Boomers:

Tabela 2 - Lista de códigos-resumo Baby Boomers 


\begin{tabular}{|c|c|c|}
\hline \multicolumn{3}{|c|}{ Listagem dos códigos dos conteúdos analisados: Geração Baby Boomers } \\
\hline Atributos & Consequências & Valores \\
\hline 1 - Estillo do automóvel & \multicolumn{2}{|c|}{16 - Orgulho da indústria brasilei 26 - Segurança financeira } \\
\hline 2 - Conforto e opcionais do automóvel & 17 - Preço acessível & 27 - Seguranç/amor familiar \\
\hline 3 - Manutençāo do automóvel & 18 - Colecionismo & 28 - Realização pessoal \\
\hline 4-Marca Ford & 19- Qualidade & 29 - Auto-estima \\
\hline 5 - Tamanho & 20 - Nostalgia/Infância & 30 - Nostalgia/saudosismo \\
\hline 6-Mecânica do automóvel & 21 - Confiança no automóvel & 31 -Status \\
\hline 7 -Ronco e potência do motor & 22 - Inovação & 32 - Amor/Familia \\
\hline 8 - Robustez do automóvel & 23 - Dirigibilidade & 33 - Estou colaborando com o pais \\
\hline 9 - Estabilidade do automóvel & \multicolumn{2}{|c|}{24 - Velocidade do automóvel } \\
\hline 10 - Acabamento e qualidade & \multirow{2}{*}{\multicolumn{2}{|c|}{25 - Design chama atençāo }} \\
\hline 11 - Economia & & \\
\hline \multicolumn{3}{|l|}{12 - Esportividade do automóvel } \\
\hline \multicolumn{3}{|l|}{13 - Custo $x$ beneficios } \\
\hline \multicolumn{3}{|l|}{14 - História/fama do automóvel } \\
\hline 15 - Marketing da marca Ford & & \\
\hline
\end{tabular}

Fonte: os autores (2019)

A metodologia empregada na análise dos dados desta geração é a mesma usada para a análise feita da Geração X. Foram adicionados pontos de corte em atributos, consequências e valores, a fim de focar a pesquisa nos elementos mais significativos que fora respectivamente: Segurança, Amor familiar como Nostalgia, Saudosismo e Segurança Financeira.

\section{Segurança e Amor Familiar}

Conforme Oliveira (2010), são características desta geração a questão do respeito e importância que a Geração Baby Boomers dá para a família como instituição. Foi extraído das entrevistas que a aquisição do Maverick teve motivações que buscavam um bem estar familiar, um zelo pelos ocupantes do carro, a comodidade dos mesmos, a percepção de andar em um carro esportivo, robusto e seguro, com um motor v8 com um ronco reconhecido e admirado. E a relativo custo baixo de aquisição, tudo isto somado levou a sensação de segurança familiar.

[...]aquilo que era carro, potente seguro, confortável cabia a família toda, hoje não tem nada disso[...] (Entrevistado 14, 68 anos).

[...]eu levava a família toda e ainda as malas, e chegava na praia, com a maior segurança, a família adorava fazer passeios nos finais de semana[...] (Entrevistado 13, 75 anos). 
[...]olha eu gostava porque me sentia seguro para sair com meus filhos nestas estradas perigosas, mas a minha esposa e meus filhos gostavam mais ainda, era um grande programa familiar[...] (Entrevistado 16, 72 anos).

\section{Nostalgia e Saudosismo}

Curiosamente, são valores também encontrados na Geração X, porém lá é o mais citado e importante. Na pesquisa, a Geração Baby Boomers, a Nostalgia assume um papel de motivação em adquirir um Maverick. Todo sentido nostálgico vem da comparação do que se tem hoje, do que o mercado oferecia na época comparado com os importados que vinham ao Brasil.

O Maverick é citado como carro de desenho exclusivo, dos mais bonitos carros nacionais. A questão da independência, de ver o Maverick como um veículo que conduz a um sentimento de liberdade, mencionado por Erickson (2011) como sendo característica da Geração X.

A Marca Ford, através do Maverick, soube explorar este ideal de vida dos jovens dos anos 70 o que nos leva a entender que a nostalgia é um dos valores que leva ou levou a Geração dos Baby Boomers a adquirir um Maverick com a lembrança dos carros importados americanos:

Tu comprar um carro e saber que aquele carro foi campeão das provas, das diversas modalidades que tinham, era a versão brasileira do campeão da Ford, o Mustang, que até hoje ainda é vendido no mercado americano. Que carro maravilhoso, muito melhor que os Opalas e os Dodge, isso é uma satisfação para o proprietário. (Entrevistado 12, 52 anos).

A mecânica dele principalmente, era igual ou até superior que os importados, o motor v8 era muito bom, o melhor que tudo que eu já vi. (Entrevistado 11, 64 anos).

\section{Segurança Financeira}

Os entrevistados mencionam o preço acessível, valor de revenda, peças e manutenção, em geral como atributos fortes que geram o valor terminal de segurança financeira. O carro naquela época era visto como 
O Ronco do V8 Objeto de Desejo: Estudo de Caso do Automóvel Ford MaverickemDiferentes Gerações sob a Ótica da Cadeias Meio Fim 22

um investimento de manutenção barata e fácil e de durabilidade acima do comum:

Sempre gostei e sempre tive [...] acontece que na época [...] a gente sempre lutou com dificuldade ne? Foi um carro que gastava um pouquinho, era meio beberrão, mas até compensava por ser um carro bom, rápido bom de vender e dava pouca oficina. (Entrevistado 15, 72 anos).

Ah, já tive uns 5 Mavericks [...]sempre ganhei dinheiro na venda, nunca tive problemas. Eu tenho hoje, um 76 é o único que não tem negócio, é do meu uso e vai ficar para o meu filho. Eu vou deixar para ele, pois gosta também. Essa questão do carro, da marca passa de pai para filho, e até já tenho neto aí com 3 anos de idade que já briga pelo Maverick também.(Entrevistado 17, 75 anos).

Para Erickson (2011) os Baby Boomers esperam que os filhos sejam bem-sucedidos na vida. O sentimento de ter na família um carro, que é considerado um bem valorizado, e repassá-lo a próxima geração traz consigo o ideal de confiança, de vida melhor, e segurança financeira.

\section{CONCLUSÕES E IMPLICAÇÕES GERENCIAIS}

A citação a seguir está presente no livro "Esculpir o tempo", de Andrei Tarkovski (2002) onde o autor tentou explicar a importância dos valores associando o objeto em questão, a uma história. Por exemplo, "uma bengala, que não seria somente algo que ajudaria alguém a caminhar, mas na realidade uma peça utilitária que traz consigo uma história de vida, da vida das pessoas "nos velhos tempos". Assim, a potência e o ronco inconfundível de um clássico V8 Marverick, o tornaram admirado e almejado por muitos consumidores amantes dos automóveis, imortalizado em vários filmes de Hollywood (Mad. Max, Velozes e Furiosos e Bullitt). Portanto, possuir um automóvel deste estilo reflete na vida das pessoas histórias passadas que vão além do sentido utilitário do produto (Solomon, 2016). 
Em suma, este estudo buscou avaliar os valores em comum das gerações associado ao automóvel como as implicações teóricas e gerenciais deste comportamento de consumo nostálgico e geracional.

\section{Valores em comum das Gerações}

O estudo alcançou um valor abstrato comum nas duas gerações: Nostalgia e Saudosismo. Segundo a percepção captada pelas entrevistas, o Maverick representava o modo de vida vinculado com os costumes dos brasileiros da década de 1970. Nesta década o Brasil, cresceu no ramo dos transportes e obteve financiamento expandindo sua malha rodoviária. $\bigcirc$ Maverick foi considerado o carro que a classe média podia comprar na década de 1970, assim, a geração dos Baby Boomers, comprou e utilizou o Maverick e depois repassando para seus filhos (Geração X) estes valores, sentimentos, experiências e impressões. Repassaram a geração seguinte, um carro brasileiro diferenciado, esportivo potente e de qualidade, extremamente desejado pelos jovens da época e com ótimo custo. Uma geração influenciou a outra. A Geração Baby Boomers viu florescer a indústria brasileira automotiva. Hoje, esta geração ainda tem a necessidade de valorizar o passado, o carro que utilizou e serviu à família ganhando um alto grau de satisfação. Da mesma forma, na Geração X, o valor nostalgia e saudosismo foi apontado como principal valor na pesquisa desenvolvidos por características sensoriais, emotivas e de fantasias do consumidor. A Nostalgia é apontada como uma grande impulsora no comportamento dos consumidores (Hutcheon, 1998).

Indivíduos nostálgicos e saudosistas acomodam seu comportamento, resgatando algo do passado. A pesquisa apontou que esse valor para a Geração X está ligado à questão da tentativa de resgate de uma época passada. Por influência de seus pais, ou amigos, essa época passada foi considerada importante e marcante na suas histórias de vida. Outro ponto importante e a questão do colecionismo, que vem ligado ao valor nostalgia, de maneira que colecionar um bem, no caso o Maverick, é pertencer a um 
O Ronco do V8 Objeto de Desejo: Estudo de Caso do Automóvel Ford MaverickemDiferentes Gerações sob a Ótica da Cadeias Meio Fim 24

grupo de referência. Esse sentimento de colecionar leva a um sentimento de pertencer a uma comunidade que se envolve por uma causa, movimento, vontade ou marca (Aaker, 2007; Lyu e Kim, 2020). O envolvimento com um produto nestas comunidades, neste caso "grupos apaixonados automóvel Maverick", remete a uma recordação que trás resignificados a pertencer a movimentos que tornam o passado presente por intermédio do uso de produto ou marca (Fleck, Abdala e Trott, 2008; Lyu e Kim, 2020; Silva et al., 2020).

\section{Implicações Teóricas}

O objetivo principal desta pesquisa foi compreender 0 comportamento das gerações em relação ao automóvel Maverick, um automovel campeão de venda da marca Ford no Brasil, na época de seu lançamento e nos dias atuais. Saudosismo e Nostalgia, bem como a influência entre gerações foram os pontos de destaque que apareceram utilizando a técnica do Laddering.

Segundo Fleck, Abdala e Trott (2008), homens e mulheres mostram sentimentos de nostalgia em magnitudes desiguais. Nos homens, a nostalgia apresenta-se mais em equipamentos de esporte e automóveis; já nas mulheres, a nostalgia é mais notada em lembranças como fotografias, bibelôs, entre outros. Para dos Santos e Johnston (2018) existe um escalonamento de prioridades quando associamos memória e lembranças sobre um produto ou serviço levando o consumidor a ter sentimentos nostálgicos e geracionais.

Foi observada na pesquisa a importância do estudo de gerações e a profunda ligação entre as gerações com produtos associado as gerações Baby Boomers e X.

Verificou-se que no lançamento do Maverick no Brasil existia uma oportunidade, um segmento de mercado não atendido entre os populares e os de luxo, ou seja, existia a necessidade de um veículo com custo menor que os importados, mas que tivesse os atributos destes. Em especial para que 
à classe média, tivesse a sensação de possuir um carro "um Mustang Brasileiro" com desenho avançado e mecânica confiável, potencia do motor com um ronco reconhecido, conferindo assim um status ao comprador para os padrões da época. A Ford acertou ao oferecer, para a classe média, um carro com luxo e uma versão esportiva única com um preço menor que os concorrentes Galaxie e Dodge, que eram maiores, mais caros e de consumo ainda mais alto. A questão dos opcionais oferecidos e a forma de como podiam ser escolhidos rendeu ao carro uma diversificação de modelos e estilos.

A Geração Baby Boomers, que consumiu o Maverick na década de 1970, atestou suas percebidas qualidades, assimilou toda campanha de marketing que a Ford para promover o Maverick, é também viveu a crise do petróleo e assim o ciclo de vida deste automóvel de destaque foi encurtadoe terminando antes dos anos 80, por razões econômicas. Essa geração percebeu na valorização, no baixo consumo de combustível e no custo baixo de manutenção atributos que nortearam o seu principal valor e, por consequência, passou esse sentimento a uma seguinte geração.

Por sua vez, a Geração X, que nos dias de hoje ainda possui um Maverick, notadamente, representa um resgate dos valores percebidos por seus pais, e amigos próximos que viveram uma época saudosa, provocando o desejo de preservação da história que o carro representa fazendo parte de um movimento que remete a nostalgia e memórias suas e de seus familiares. Por outro lado, pode ocorrer um desejo apaixonado dos consumidores destas gerações por experiências passadas em família com o automóvel. Para Kozinets, Patterson e Ashman (2017) os consumidores vivem se apaixonando por histórias, que rementem a experiências com produtos que deixam alguma memória que no futuro pode voltar ressurgindo um comportamento de uso. Em outras palavras, os consumidores podem sofrer influências emocionais por intermédio de lembranças ou experiências passadas (Lyu e Kim, 2020). Essas lembranças nos remetem a traduzir 
O Ronco do V8 Objeto de Desejo: Estudo de Caso do Automóvel Ford MaverickemDiferentes Gerações sob a Ótica da Cadeias Meio Fim 26

experiências por meio de memórias passadas que supriram necessidades e desejos reais em algum momento de nossa vida.

Todos esses atributos surgem da nossa crença como ser humano que a memória ou lembrança de algo não leva somente a uma dimensão nostálgica de um mundo que não existe mais, mas de uma orientação significativa do ser como consumidor que constrói o presente por uma determinada experiência passada que será potencializada em um horizonte futuro por comunidades, produtos, serviços ou marcas (Izquierdo, 2018; Lyu e Kim, 2020).

Esta pesquisa tem algumas limitações, um fator limitador foi de considerar uma amostra de 47 consumidores abordados em feiras de colecionadores e carros antigos, o que gerou resultados baseados na percepção desta parcela de consumidores específicos. Além disso, o estudo foi conduzido por meio de um roteiro aberto, que foi ampliado com apoio das respostas dos entrevistados. Outra limitação está relacionada aos resultados que poderiam ser ampliados com outros instrumentos e formas de observação.

Dessa forma, sugere-se estudos futuros que ampliem o escopo desta pesquisa, considerando uma amostra mais abrangente não só com colecionadores e proprietários do Maverick, mas com aqueles que tem a intenção de adquirir este automóvel. Também se recomenda a realização de um estudo que amplifique a pesquisa considerando as oito relações (A-C- V) e os atributos concretos e abstratos para que se possa analisar as consequências funcionais versus as psicológicas dos consumidores de automóveis antigos, como os consumidores do Ford Maverick.

\section{Implicações Gerenciais}

O estudo mostra a importância de empresas que utilizaram uma estratégia de diferenciação, orientação ao cliente, conforme a Ford fez com o Maverick, que rapidamente se tornou um campeão de vendas. Quaisquer produtos onde o direcionamento de mercado seja um segmento ou público específico, o corte geracional a que pertence deve ser levada 
em conta pois esse consumidor tem sua preferência por certas características e atributos, que poderão tornar-se valores pessoais. Um dos aspectos interessantes a analisar é o senso de pertencimento desses grupos. Além de analisar como são estimuladas as ações que possam potencializar este sentimento.

O correto entendimento dessa cadeia potencializará e direcionará as ações de marketing para o sucesso. Assim, o constante estudo dessas evoluções de valores presente nas gerações, podem auxiliar na decisão de um posicionamento no mercado e na comunicação de produtos fora de linha ou que tiveram um destaque no mercado consumidor.

\section{REFERÊNCIAS}

Aaker, D. A. (2007). Construindo marcas fortes. Bookman Editora.

Allen, M. W. (2001). A practical method for uncovering the direct and indirect relationships between human values and consumer purchases. Journal of consumer marketing. https://doi.org/10.1108/07363760110385983

Bardin, L. (2011) Analise de Conteudo. (Tradução: Luís Antero Reto, Augusto Pinheiro). São Paulo: Edições 70.

Barth, F. (1996). 18 Ethnic Groups and Boundaries (1969). Theories of Ethnicity: A Classical Reader, 294.

Belk, R. W. (1995). Collecting as luxury consumption: Effects on individuals and households. Journal of economic psychology, 16(3), 477-490. https://doi.org/10.1016/B978-0-12-374522-4.00004-4

Brown, S; Kozinets, R.; Sherry, J. (2003) Teaching old brands new tricks: retro branding and the revival of brand meaning, Journal of Marketing, 67 (3), 1933. https://doi.org/10.1509/jmkg.67.3.19.18657

Carvalho, G. B., \& dos Santos, M. J. (2019). Comportamento do Consumidor de Produtos de Acabamentos. Marketing \& Tourism Review, 4(2). https://doi.org/10.29149/mtr.v4i2.5089

Corsten, M. (1999). The time of generations. Time \& Society, 8(2-3), 249-272. 
O Ronco do V8 Objeto de Desejo: Estudo de Caso do Automóvel Ford Maverick emDiferentes Gerações sob a Ótica da Cadeias Meio Fim 28

Datafolha (2008) Jovens brasileiros. São Paulo, 30 jul. 2008. Disponível em: <http://datafolha.folha.vol.com.br/ po/ver_po.php?session=700>. Acesso em: 30 set. 2020.

dos Santos, D. S., \& Johnston, D. M. M. (2018). Um Estudo Sobre Atributos Consequências E Valores Relacionados Ao Consumo Colaborativo. Marketing \& Tourism Review, 3(3). https://doi.org/10.29149/mtr.v3i3.4622

Engel, J.F.; Blackwell, R. D.; Miniard, P. W. (2000). Comportamento do Consumidor. 8 ed. Rio de Janeiro: LTC

Erickson, T. J. (2011). E agora, geração X? Como se manter no auge profissional e exercer a liderança plena numa época de intensa transformação. Rio de Janeiro: Elsivier.

Fleck, J. P. S.; Abdala, P. R. Z.; Trott, S. (2008) Nostalgia e marketing: Revisão de Conceitos e A Validac, ão da Escala de Tendencia Nostalgica de Holbrook no Brasil. Encontro de Marketing da ANPAD, 3. Anais... Curitiba: ANPAD.

Gil, A. C. (2014) Métodos e técnicas de pesquisa social. 6. ed. São Paulo: Atlas.

Gregson, P.W. (2011) Clássicos do Brasil: a história do Maverick. Editora Alaúde, SP.

Gutman, J. (1981)."A Means-End Model For Facilitating Analyses of Product Markets Based on Consumer Judgement", in NA - Advances in Consumer Research Volume 08, eds. Kent B. Monroe, Ann Abor, MI : Association for Consumer Research, Pages: $116-121$.

Holbrook, M. B., \& Hirschman, E. C. (1982). The experiential aspects of consumption: Consumer fantasies, feelings, and fun. Journal of consumer research, 9(2), 132-140. https://doi.org/10.1086/208906

Izquierdo, I. (2018) Memória, 3a Ed. Editora ArtMed, Porto Alegre.

Jones, J. P. (2004). publicidade na construção de grandes marcas, A-Grupode mídia. NBL Editora.

Kotler, P., \& Keller, K. L. (2006). Marketing para o século XXI. Pearson PrenticeHall.

Kozinets, R., Patterson, A., \& Ashman, R. (2017). Networks of desire: How technology increases our passion to consume. Journal of Consumer Research, 43(5), 659-682. https://doi.org/10.1093/jcr/ucw061 
Lyu, J., \& Kim, J. (2020). Antecedents of Social Media Induced Retail Commerce Activities: Impact of Brand-Consumer Relationships and Psychological Sense of Community. Journal of Interactive Advertising, (just accepted), 1-34. https://doi.org/10.1080/15252019.2020.1769513

Murphy, H. (2000). They've gotta have it. Forbes Global Life. Dezembro, 2000.

Oliveira, S. (2010). Geração Y: o nascimento de uma nova versão de líderes. São Paulo: Integrare.

Peter, J. P.; Olson, J. C. (2010). Comportamento do consumidor e estratégia de marketing. Trad. Beth Honorato. 8 ed. Porto Alegre: AMGH.

Rezsohazy, R. (2001). Sociology of values. International Encyclopedia of the Social \& Behavioral Sciences.

Reynolds, T. J.; Gutman, J. (1988). Laddering theory, method, analysis, and interpretation. Journal of Advertising Research, New York, v. 28, p. 11-31, Feb.Mar.

Reynolds, T. J., \& Gutman, J. (2001). Laddering theory, method, analysis, and interpretation. In T. J. Reynolds \& J. C. Olson (Eds.), Understanding consumer decision making: The means-end approach to marketing and advertising strategy (p. 25-62). Lawrence Erlbaum Associates Publishers.

Rokeach, M. (1972). Beliefs, attitudes and values: A theory of organization and change. Jossey-Bass.

Silva, L. E. N., Neto, M. B. G., da Rocha Grangeiro, R., \& Carneiro, J. S. (2020). Consumo de produtos tecnológicos: da funcionalidade ao status. Marketing \& Tourism Review, 5(1). https://doi.org/10.29149/mtr.v5i1.5653

Slater, J. S. (2001). Collecting brand loyalty: A comparative analysis of how Coca-Cola and Hallmark use collecting behavior to enhance brand loyalty. ACR North American Advances.

Solomon, M. R. (2016). O Comportamento do consumidor:- comprando, possuindo e sendo. Bookman Editora.

Tarkovski, A. (2002). Esculpir o tempo. São Paulo: Martins Fontes, 2002.

Vinson, D. E., Scott, J. E., \& Lamont, L. M. (1977). The role of personal values in marketing and consumer behavior. Journal of marketing, $41(2), 44-50$. https://doi.org/10.1177/002224297704100215 
Walker, B. A., \& Olson, J. C. (1991). Means-end chains: Connecting productswith self. Journal of business research, 22(2), 111-118. https://doi.org/10.1016/0148-2963(91)90045-Y

Wasson, C. R. (1978). Dynamic competitive strategy \& product life cycles. Austin Press.

Woodruff, R. B.; Gardial, S. F. (1969). Know your customer: new approaches to understanding customer value and satisfaction. Malden, MA, USA: Blackwell Business.

Zeithaml, V. A., Parasuraman, A., Berry, L. L., \& Berry, L. L. (1990). Delivering quality service: Balancing customer perceptions and expectations. Simon and Schuster. 